\title{
ANÁLISE DE TÍTULOS DE ARTIGOS DE PESQUISAS PUBLICADAS EM UM PERIÓDICO BRASILEIRO DE ENFERMAGEM
}

\author{
David Lopes Neto ${ }^{1}$ \\ Marcos Venícios de Oliveira Lopes ${ }^{2}$ \\ Marta Maria Coelho Damasceno ${ }^{3}$ \\ Maria de Nazaré de Oliveira Fraga ${ }^{3}$
}

Lopes D Neto, Lopes MVO, Damasceno MMC, Fraga MNO. Análise de títulos de artigos de pesquisas publicadas em um periódico brasileiro de enfermagem. Rev Latino-am Enfermagem 2002 janeiro-fevereiro; 10(1):77-84.

O estudo analisa títulos de pesquisas publicadas em um periódico de enfermagem nos anos de 1997 e 1998. Os dados foram coletados através de formulário e organizados mediante a utilização do sistema computacional EPI-INFO 6, sendo que a análise fundamentouse em literatura nacional e internacional recente relativa a análise de relatórios de pesquisa. Os resultados, dispostos em tabelas, mostraram que a maioria dos artigos analisados apresenta uma captação parcialmente adequada dos títulos, em relação às variáveis, populações estudadas e/ou palavras-chave. Conclui-se que a avaliação dos títulos de pesquisas em enfermagem ainda necessita de uma maior atenção, tendo em vista que grande parte das bases de dados, acessadas por pesquisadores, trabalha com a divulgação das pesquisas somente por meio de seus títulos.

DESCRITORES: pesquisa em enfermagem, normas

\section{ANALYSIS OF TITLES OF RESEARCH ARTICLES PUBLISHED IN A BRAZILIAN NURSING JOURNAL}

This study analyzes titles of research works published in a nursing journal in 1997 and 1998. Data were collected through forms and organized by using the EPIIINFO 6.0 computer program. The analysis was based on recent national and international literature concerning the analysis of research reports. Results, which have been disposed in tables, showed that most of the analyzed articles presented a partly adequate titles in relation to variables, studied populations and/or key words It was concluded that the evaluation of titles in nursing research still requires more attention since a large number of databases aused by researchers only publicize research work means of its titles.

KEY WORDS: nursing research, norms

\section{ANÁLISIS DE TÍTULOS DE ARTÍCULOS DE INVESTIGACIONES PUBLICADAS EN UNA REVISTA BRASILEÑA DE ENFERMERÍA}

El estudio analiza los títulos de investigaciones publicadas en una revista de enfermería en los años de 1997 y 1998. Los datos fueron recolectados a través de formulario y organizados por medio del uso del programa EPI-INFO 6.0. El análisis se fundamentó en la literatura nacional e internacional reciente, relacionada con el análisis de informes de investigación. Los resultados, presentados en tablas, mostraron que la mayoría de los artículos analizados presenta una captación parcialmente adecuada de los títulos, en relación con las variables, poblaciones estudiadas y/o palabras claves. Se concluye que la evaluación los títulos de investigaciones en enfermería necesita una atención mejor ya que gran parte de las bases de datos buscadas por los investigadores, trabaja con la divulgación de las investigaciones solamente por medio de sus títulos.

DESCRIPTORES: investigación en enfermería, normas

\footnotetext{
${ }^{1}$ Professor Assistente da Escola de Enfermagem de Manaus da Universidade do Amazonas, Doutorando em Enfermagem DENF/FFOE/UFC, e-mail: den@baydenet.com.br; ${ }^{2}$ Professor da Universidade Estadual do Ceará, Doutorando em Enfermagem DENF/FFOE/UFC, Bolsista da CAPES; ${ }^{3}$ Professor do Departamento de Enfermagem da Universidade Federal do Ceará, Doutor em Enfermagem DENF/FFOE/UFC
} 


\section{INTRODUÇÃO}

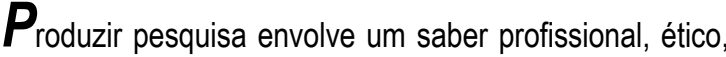
moral e, principalmente, rigor científico. Produzir pesquisa é, também, divulgar, publicar. Produzir pesquisa é um ato de comunicação do pesquisador, com uso de uma linguagem técnico-científica sobre as informações do seu estudo. Essa comunicação se efetiva pelo uso de diferentes mecanismos, para a composição de monografias, dissertações, teses, livros, artigos de periódicos, resumos, notas prévias, apresentações em comunicações orais, e até sessões de posters.

O presente estudo trata da análise de títulos de artigos de pesquisas, considerando serem estes sínteses de pesquisas concluídas. Artigos de pesquisas são relatórios sintetizadores dos principais elementos de uma investigação científica, com a finalidade de disseminar a comunicação do estudo, em especial, entre os profissionais da área para a qual o periódico está direcionado ${ }^{(1)}$.

A tradição filosófico-acadêmica brasileira identifica a pesquisa científica quando esta é comunicada. Há, porém, uma tendência de generalizar, como pesquisa, certos trabalhos acadêmicos de natureza didática. Clarificando esta errônea concepção que ainda permeia os meios acadêmicos, pode-se definir pesquisa como "trabalho empreendido metodologicamente, quando surge um problema, para o qual se procura a solução adequada de natureza cientifica" ${ }^{\prime 2)}$. Essa definição, por certo, nos remeteu à rever alguns trabalhos por nós realizados, através da análise crítica.

Não seria desnecessário enfatizar que a análise é um processo metodológico de decomposição de um todo em partes enquanto que a crítica é uma contraposição fundamentada no exame minucioso dos conceitos de um texto, da observância do estabelecimento de ligação ou de separação entre os dados de um determinado estudo ${ }^{(3)}$.

A análise aqui procedida, como toda crítica, não se opõe ao pensamento dos autores de artigos científicos, nem se estabelece como julgamento absolutamente verdadeiro, contrapondo-se a um conjunto de idéias. Trata-se, na verdade, de um trabalho intelectual, interpretativo e explicativo de um conteúdo, para tentar desvelar o que está silenciado nas suas entrelinhas, tendo em vista que 0 exercício da crítica tenta fazer falar o silêncio, movimentar um pensamento que possa desvendar o silêncio contido em outros pensamentos e discursos ${ }^{(3)}$. Serve essa afirmação, realmente, de substrato ao objeto do estudo que culminou na elaboração deste artigo.

Em nenhum momento fomos levados a desencorajar a imaginação criativa dos pesquisadores da enfermagem, na elaboração de títulos de pesquisas motivadores e poéticos. Não obstante, somos pelo estudo, à luz da racionalidade das revoluções científicas popperianas para, possivelmente, explicar o critério de cientificidade dos relatórios de pesquisas, desde a construção dos seus títulos, servindo-se dos seus pressupostos na tentativa de justificar que a linguagem escrita deve ser econômica em palavras e vista sempre como uma condicionante de objetividade e veracidade. A objetividade está baseada em uma crítica racionalista, com uma abordagem crítica tradicional, com o propósito de alavancar, com mutualidade de análises críticas, a pesquisa científica ${ }^{(4)}$.

Em meio aos antigos e aos novos pesquisadores, a pesquisa em enfermagem vem se defrontando com a carência de estudos que levem a uma análise crítica da sua produção científica. Para os autores, formular um problema não foi difícil, dada a experiência acumulada na profissão e na pesquisa em enfermagem, ao longo de duas décadas, o que lhes serviu de respaldo para levantar várias questões acerca das situações que ocorriam e ocorrem dentro dos cenários técnico-científicos da enfermagem brasileira. Dentro desse contexto, uma dessas situações está relacionada à elaboração de títulos de pesquisas de enfermagem. E aqui cabe uma indagação: Será que os títulos das pesquisas de enfermagem estão traduzindo 0 que realmente foi estudado? 0 problema se configura à medida em que, ao participarmos de eventos específicos da categoria, foinos dado observar que alguns trabalhos traziam seus títulos de forma pouco objetiva, por vezes criando dificuldades para a identificação de algum tipo de interesse que a matéria pudesse despertar. Estas observações, inclusive, levaram os autores da pesquisa a reavaliarem alguns dos seus trabalhos, o que lhes permitiram verificar que os títulos não expressavam, fidedignamente, os objetos de estudo, donde, certamente, serem também passíveis de análise crítica.

Na literatura em geral, alguns estudiosos têm relatado as preocupações com o rumo que os títulos das pesquisas vêm tomando, fato este que também serviu de objeto de reflexão na área da enfermagem, em que vem sendo assinalado que títulos de artigos veiculados em periódicos não contemplam, em sua maioria, o conteúdo do trabalho ${ }^{(5)}$

Neste estudo buscamos preencher algumas lacunas existentes, adotando uma opção crítica direcionada para a análise dos títulos de pesquisas em enfermagem, publicadas em revista especializada de circulação nacional, tendo por intuito recomendar estratégias quanto à redação e ao estilo técnico, para a criação de títulos de pesquisas.

Dentro de uma visão interdisciplinar do problema, autores de outras áreas do conhecimento têm expressado preocupações com o rigor científico nas pesquisas, elaborando materiais normativos direcionados para a construção de relatórios científicos. Entre eles destaca-se a compreensão de que as normas documentárias para realização de trabalhos de pesquisas são agentes facilitadores da comunicação do trabalho intelectual, sem apresentar quaisquer 
intenções cerceadoras da liberdade de expressão na forma da linguagem escrita. Sendo assim, a normalização não é um fim, mas um meio que leva o pesquisador ao rigor científico que deve nortear a elaboração do seu trabalho intelectual ${ }^{(6)}$. Sobre a elaboração e divulgação de trabalhos científicos, vale considerar que o pesquisador deve buscar um estilo claro, conciso e objetivo que se traduza em linguagem correta, técnica, porém simples ${ }^{(7)}$. Atendo-se a tais aspectos, os títulos de pesquisas escritos com clareza, objetividade e tecnicamente corretos devem traduzir a essência do objeto estudado.

\section{METODOLOGIA}

Trata-se de uma pesquisa documental, exploratóriodescritiva, de natureza quantitativa, realizada através de levantamento de dados por meio de um formulário apropriado (Anexo 1). Diante das várias fontes que poderiam ser utilizadas nesta etapa, a escolha recaiu nas pesquisas publicadas em um periódico de enfermagem, referente aos anos de 1997 e 1998, por estarem seus exemplares disponíveis para consulta quando da realização da coleta. A análise dos dados fundamentou-se em parâmetros indicados por diversos autores $^{(1,8-10)}$. Os dados foram coletados e tabulados através do sistema computacional EPI-INFO 6.0, sendo os resultados dispostos em tabelas e quadros. Por formalidade ética, foram ocultadas quaisquer informações que pudessem vir a identificar a origem da pesquisa, atendidas, no caso, as normas disciplinadoras para elaboração de pesquisas. Com isso, foi mantido 0 anonimato dos pesquisados, sendo todos os exemplos citados fictícios, muito embora criados a partir dos dados reais, resultantes de coleta.

\section{ANÁLISE E DISCUSSÃO DOS RESULTADOS}

A análise dos dados apontou para a incorreção de alguns títulos, fato que contribuiu para a perda do seu direcionamento, em relação aos objetos de estudo, podendo levar ainda os leitores a constantes buscas de referências teóricas sem a devida resposta. Autores consultados ressaltam que a pesquisa deve oferecer contribuição, de forma indireta, aos leitores de pesquisas científicas, na busca que empreendem, sem gerar ansiedade ou frustração ${ }^{(1)}$. Ressaltamos que títulos exuberantes, construídos na tentativa de por à mostra uma linguagem filosófica e científica, não raro deixam de expressar o conteúdo trabalhado. 0 uso de uma linguagem rebuscada pode decepcionar os leitores, quando o ideal seria motiválos.

De acordo com o levantamento realizado, durante o biênio em que se desenvolveu a pesquisa, foram publicados 68 artigos referentes a pesquisas concretas, sendo 25 no ano de 1997 e 43 em 1998. A diferença ficou por conta de no último período, terem sido lançados cinco números da revista, normalmente com periodicidade trimestral. A média de artigos publicados por número da revista é igual a onze.

Apesar da maioria dos artigos analisados apresentarem títulos considerados adequados, de acordo com o referencial de análise utilizado, há uma quantidade significativa de artigos com títulos apresentando uma captação parcialmente adequada (Tabela 1), não condizendo com o conteúdo expresso no corpo do trabalho e, portanto, sendo objeto de críticas por incorreções que podem comprometer sua qualidade.

Tabela 1 - Distribuição dos artigos de acordo com a captação do título, em relação às variáveis, população estudadas e/ou palavraschave. Fortaleza, 1999

\begin{tabular}{lcc}
\hline \multicolumn{1}{c}{ CAPTAÇÄO } & $N$ & $\%$ \\
\hline Adequada & 33 & 48,52 \\
Parcialmente adequada & 35 & 51,48 \\
\hline TOTAL & 68 & 100 \\
\hline
\end{tabular}

As palavras-chave foram parcialmente captadas pelos títulos, comprometendo o uso de vários artigos como referência bibliográfica. É importante lembrar que a catalogação de obras se dá por autor, assunto e título como forma de facilitar a consulta do leitor, sendo muito importante a avaliação positiva quanto à utilidade de um artigo por representar economia de tempo ${ }^{(11)}$. A análise empreendida, além de ser um registro de preocupação, poderá ser uma fonte de reflexão crítica acerca da importância que deve ser dada aos títulos de pesquisas.

$\mathrm{Na}$ Tabela 2, as incorreções abrangeram o uso inadequado de figuras de linguagem: metáfora $(7,35 \%)$, pleonasmo $(5,88 \%)$, metonímia (13,24\%), hipérbole $(19,12 \%)$ e catacrese $(1,47 \%)$.

Tabela 2 - Linguagens e figuras de linguagem presentes em títulos de artigos de pesquisa em enfermagem. Fortaleza, 1999

$$
\text { LINGUAGEM }
$$

FIGURA DE LINGUAGEM DENOTATIVA CONOTATIVA

\begin{tabular}{lccc}
\hline Nenhuma & 36 & - & 52,94 \\
Metáfora & - & 05 & 7,35 \\
Metonímia & - & 09 & 13,24 \\
Hipérbole & - & 13 & 19,12 \\
Pleonasmo & - & 04 & 5,80 \\
Catacrese & - & 01 & 1,47 \\
\hline TOTAL & 36 & 32 & 100 \\
\hline
\end{tabular}


O uso exagerado de figuras de linguagem torna 0 título rebuscado e cientificamente empobrecido. Se usadas para traduzir o cotidiano, elas merecem reflexão mais apurada por parte do pesquisador, para que não haja comprometimento da estética, da consistência e da clareza semântica das palavras. No exemplo "Como tivesse acertado na megasena: a reabilitação de um paciente politraumatizado", percebe-se que a linguagem coloquial se faz presente, interferindo na linguagem técnica que ficou relegada ao sub-título.

Analiticamente, o uso de metáforas como figura de linguagem, deixando subentendida uma comparação, busca expressar os pensamentos dos autores quanto aos seus estudos. Em títulos dessa natureza, tais metáforas não chegam a expressar um pensamento uniforme do objeto estudado, contudo, seus registros estão relacionados com uma certa afetividade lingüística e emocional ao ser tratada uma situação-problema, o que deve ser um sinal de alerta para o pesquisador, dado que a manifestação dos sentimentos pode interferir na pesquisa, como um todo. Sendo assim, vale estar vigilante quanto ao uso de figuras de linguagem, quando o assunto for de natureza técnica ${ }^{(10)}$.

A metáfora é um dispositivo literário tipicamente usado nas ciências sociais, um modo de re-apresentar uma coisa em termos de outro, é parte integrante dos textos científicos como visões particulares dos autores ${ }^{(12)}$. Na construção de teses, livros e artigos a utilização de metáforas constitui-se um exercício teórico sério, pelo que deve ganhar melhor atenção até porque serve para iluminar o trabalho. Logo, o uso da metáfora é referido, dentro do texto, como recurso capaz de enriquecê-lo e torná-lo obra de arte, o que não pode acontecer nos títulos das pesquisas.

O mau uso de hipérboles $(19,12 \%)$, detectado no estudo, chegou a comprometer a qualidade dos resultados e, se tais figuras forem expressas no título, podem levar a uma pseudo-interpretação do que intuiu transmitir. Um caso a exemplificar seria tratar como sujeitos da pesquisa "futuros técnicos de enfermagem", quando os sujeitos são "estudantes do curso técnico em enfermagem". Sobre a questão, aplica-se o princípio do terceiro excluído, no qual entre as duas possibilidades contrárias "futuros técnicos de enfermagem" e "estudantes do curso de técnico em enfermagem", não há lugar para uma terceira "estudantes do curso técnico em enfermagem são futuros técnicos em enfermagem", considerando que nem todos os estudantes do curso técnico em enfermagem, colarão grau como técnicos em enfermagem ${ }^{(13)}$.

Alguns títulos valorizaram o marketing publicitário, em detrimento da clareza, da concisão e da objetividade do título, sem expressar, em uma linguagem científica, as variáveis, as populações estudadas e/ou as palavras-chave (Tabela 3). Os títulos precisam e devem motivar os leitores à pesquisa, mas não como fonte enganosa de busca de assuntos ou temáticas que não foram objeto de estudos, o que pode ocasionar falta de credibilidade no periódico, além da perda de tempo aos leitores. Alguns autores afirmam que o título de pesquisa deve ser claro e objetivo, podendo ser completado com um sub-título. Deve ser escrito na mesma língua do texto, seguido de versões para outros idiomas, quando for do interesse da revista. É sempre oportuno evitar abreviaturas, parênteses e fórmulas que dificultem a compreensão do artigo, colaborando com a normalização de títulos de pesquisas científicas de maneira clara e objetiva ${ }^{(8)}$.

Tabela 3 - Qualidade do estilo científico de títulos de artigos de pesquisa em enfermagem. Fortaleza, 1999

\begin{tabular}{lcc}
\hline \multicolumn{1}{c}{ QUALIDADE DO ESTILO } & SIM & NÄO \\
\hline Clareza & 45 & 23 \\
Concisẫo & 56 & 12 \\
Objetividade & 36 & 32 \\
Ambigüidade & 15 & 53 \\
Prolixidade & 12 & 56 \\
Imprecisấ0 & 25 & 43 \\
Generalidade & 05 & 63 \\
\hline
\end{tabular}

O lembrete de que o título deve ser escrito com capricho, evitando-se títulos que são frases, perguntas ou algum tipo de marketing bons como manchete para a imprensa, mas não tanto para artigos de pesquisas cientificas ${ }^{(9)}$, é pertinente e subsidia o que se pretende alertar neste estudo.

Atente-se para o fato de que vocábulos não são definidos, operacionalmente, para dar clareza e precisão ao título. Não obstante, a obscuridade semântica é responsável quanto ao uso de palavras ou locuções em línguas estrangeiras, em títulos que não encontram correspondência no corpo do artigo. Ao sintetizar o seu estudo, compete ao pesquisador descrever com clareza e precisão, as bases conceituais de conceitos-chave ${ }^{(1)}$. A linguagem a ser adotada em um relatório de pesquisa é a científica, caracterizada por sua clareza, objetividade e precisão ao expressar as idéias, linguagem esta que difere das linguagens coloquial e literária ${ }^{(10)}$.

Títulos longos, com mais de quinze palavras foram encontrados com percentual significativo (16,37\%), não chegando a comprometer os resultados dos estudos, mas provocando efeito antiestético, como reflexo da falta de concisão e prolixidade.

Predominou a pontuação a correta $(86,76 \%)$, mas foram detectados $13,24 \%$ artigos com má pontuação do tipo: emprego inadequado de sinais gráficos, pontos de interrogação, dois pontos, hífen, além de ausência de vírgulas, o que alterou o significado da frase que compunha o título.

Frases interrogativas e sem a devida pontuação (ponto de interrogação) foram encontradas nos títulos, indicando uma interpelação, mas sem objetivar resposta, dificultando a compreensão do título. 
No exemplo fictício - o que falam os enfermeiros sobre entrevista?- se ocultado o ponto de interrogação, a frase perde o seu sentido maior que seria o de levar o leitor a responder indiretamente a pergunta. Conseqüentemente, o objeto de estudo deixaria de estar sendo traduzido. Concordamos que frases interrogativas e/ou afirmativas, do tipo: "o peso influencia, significativamente, nos níveis de pressão arterial?" e/ou "o peso influencia significativamente nos níveis de pressão arterial", devem ser evitadas. 0 mais correto, do ponto de vista técnico e científico, seria constituir o título nestes termos: "Análise da influência do peso sobre os níveis de pressão arterial em idosos"(9).

Redundâncias fluíram nos títulos, tornando-os mais longos e, gramaticalmente, errados. A palavra interação, por exemplo, não necessita da preposição "entre" pelo fato de já incorporar o sentido de fazer parte. Seria o caso "interação mãe-filho" e não "interação entre mãe-filho" ${ }^{\text {(14) }}$, pois se usada, estaria caracterizando "superfluidade de palavras"(15).

A pesquisa permitiu que reduções fossem encontradas, sendo as siglas (17,64\%), inadequadamente incluídas nos títulos. Para o caso, a regra é bem clara, consoante orientação de que, quando mencionadas pela primeira vez, as siglas devem ter seu correspondente grafado por extenso ${ }^{(10)}$. Há, ainda, a recomendação de que um título deva ser curto, específico e sem fórmulas matemáticas ou símbolos de qualquer espécie ${ }^{(9)}$. Nesta mesma linha de raciocínio, tomando como exemplo um título genérico "AIDS no Brasil", o qual apesar de curto, não é específico, já que deixa de evidenciar 0 aspecto da AIDS abordado no estudo. Estaria sendo abordado 0 aspecto prevenção, educação em saúde ou tratamento.

Há quem recomende que sejam evitadas palavras que apenas recheiam e/ou alongam os títulos como "Introdução ao estudo de...", ou "Algumas observações acerca de...". Tais construções são esteticamente negativas e não levam a interpretações concretas ${ }^{(9)}$.

Erros de concordâncias verbal e nominal também apareceram nos títulos. Não raro, foram observados deslizes no uso do vernáculo, nos aspectos que envolvem gênero e número, como no caso: "Programa de treinamento em serviço: equipamentos de proteção individual" (Tabela 4). Na pesquisa, uma suposta falha de concordância nominal se anularia pelo uso dos vocábulos equipamentos, no plural, e proteção e individual, no singular, até porque a construção dispensa que as três palavras sejam iguais, em número. Há, no entanto, uma subordinação de natureza explicativa à primeira parte, construída no singular.

Embora pareça simples, a concordância é um mecanismo pelo qual os termos podem sofrer algum tipo de alteração em suas terminações, de forma que possam se ordenar com outras palavras, conforme a gramática da língua portuguesa ${ }^{(10)}$.
Tabela 4 - Classificação do uso de concordância verbal e nominal em títulos de artigos de pesquisa em enfermagem. Fortaleza, 1999

\begin{tabular}{lcc}
\hline CLASSIFICAÇÃO & $\begin{array}{c}\text { CONCORDÂNCIA } \\
\text { VERBAL }\end{array}$ & $\begin{array}{c}\text { CONCORDÂNCIA } \\
\text { NOMINAL }\end{array}$ \\
\hline Correta & 66 & 62 \\
Incorreta & 02 & 06 \\
\hline TOTAL & 68 & 68 \\
\hline
\end{tabular}

Sobre os documentos normalizados pelas agências oficiais, algumas considerações merecem ser registradas. A norma NBR 10719 de agosto de 1989, da Associação Brasileira de Normas Técnicas (ABNT), por exemplo, para procedimentos de apresentação de relatórios técnico-científicos, refere apenas os vocábulos títulos sub-títulos e títulos do relatório, sem mencionar quaisquer informações que possam definir as formas de apresentação e de estilo, no que se refere ao uso dos vocábulos.

Ressaltamos que as normas para publicação de trabalhos científicos dos próprios periódicos, não fazem referência quanto à construção de títulos, deixando sua elaboração a cargo do autor. A ocorrência não reflete para a comissão de editoração, tampouco para o conselho editorial, prejuízos sobre os conceitos descritos nos artigos. Os membros de ambos os colegiados são, na verdade, avaliadores dos trabalhos, como um todo, quanto às normas do periódico e quanto, também, às normas da ABNT.

\section{CONSIDERAÇÕES FINAIS}

A evolução científica e tecnológica da enfermagem tem proporcionado transformações significativas no perfil do enfermeiro, levando-o a pautar sua atuação na pesquisa, para garantir a intelectualidade e a melhoria da qualidade da assistência prestada ao usuário ${ }^{(16)}$

Ao assumirmos a posição de leitores críticos de títulos de artigos de pesquisas em enfermagem, assumimos, também, a discordância com as formas como alguns pesquisadores construíram os títulos dos artigos analisados, considerando que tanto o rigor científico, quanto o raciocínio lógico, não se fizeram bastante presentes. A arte de escrever de forma poética, não deve ser colocada de lado, mas deve prevalecer o senso crítico de que se trata de uma pesquisa científica, cujo público-alvo é, em tese, formado por profissionais da enfermagem que buscam informações nas diferentes áreas temáticas, visando ao aprimoramento e atualização técnicocientífica, o que difere de elaboração de qualquer outro veículo ou forma de comunicação escrita. 
Concordamos que a realização de uma pesquisa, sua divulgação e utilização dos seus resultados são partes integrantes de um processo ${ }^{(17)}$. Ao que nos parece, este processo de produzir, divulgar e utilizar pesquisas, passa pela formulação adequada de títulos de pesquisas, os quais, se construídos com clareza semântica e estrutural, poderão contribuir, substancialmente, para a utilização do estudo por muitas pessoas.

Considerando que os títulos estão traduzindo, parcialmente, o que realmente é estudado e que a qualidade da linguagem científica está comprometida pela forma como esses títulos estão sendo redigidos - mesclagem de linguagem coloquial e técnica, incorreções gramaticais - apresentamos algumas recomendações. Obviamente, não se trata de um novo documento normativo para elaboração de títulos de relatórios de pesquisa, mas de uma contribuição facilitadora e prática para a pesquisa em enfermagem, construída com base no que está contido na literatura, sem desprezar as expressões motivadoras e tradutoras do amor que o pesquisador tem por seu estudo. Em outras palavras, a aprendizagem do amor "não se trata de descongelar as palavras do [título] ..., mas reaquecê-las" ${ }^{\text {"(18) }}$. Afinal, as emoções não são para os títulos, mas para os corações dos pesquisadores.

A precisão ou a imprecisão de títulos de artigos de pesquisas advém de uma análise crítica e reflexiva minuciosa dos pontos a serem analisados, os quais levam ao mérito do sentido do título em traduzir os componentes essenciais da pesquisa, cabendo ao pesquisador, na qualidade de analista, revisar, com rigor e observância dos critérios de elaboração de títulos, o seu título, assim como todo o seu trabalho de investigação científica.

Com esses resultados, há de se entender que o título é uma forma de aproximação, de natureza comunicativa, entre o autor e o leitor, cada vez mais exigente de atenção. Ressalte-se que a comunicação é uma manifestação de carisma intelectual e social, complexa na sua essência, disseminada em extensas áreas do conhecimento e pesquisas científicas, com dificuldades relacionadas à eficácia e quanto à perfeição do uso da linguagem, apesar da disponibilidade dos meios de expressão( ${ }^{(19)}$.

Assim, da preocupação ao fato, fica claro que temos que atentar para a qualidade dos títulos, já que muitas bases de dados utilizadas para busca de artigos operam somente com o título do artigo.

\section{RECOMENDAÇÕES}

O estudo permitiu que fossem elaboradas algumas recomendações, as quais nos parecem de grande valia para a elaboração de títulos de pesquisas.

Merecem particular atenção:

- Uso de palavras-chave incluídas em indexadores nacionais e internacionais da área da saúde;

- Uso de um termo médio de 15 (quinze) palavras, como ideal para a construção de um título curto;

- Emprego correto da língua, em especial, nos aspectos de concordância e regência gramaticais;

- Linguagens conotativas que tenham um sentido figurado das palavras, assumindo um significado novo, quando utilizadas em títulos, devem vir como sub-título, expressando não só o significado da linguagem figurativa como também o objeto de pesquisa que deve vir como título. Há de se compreender que o uso de figuras de linguagem deve ser evitado ao máximo, em títulos e sub-títulos, permitindo-se sua colocação no corpo do trabalho, com o fito de enriquecê-lo;

- Usar título específico, sem fórmulas matemáticas, símbolos ou siglas;

A par dessas recomendações, outras mais seriam importantes, como:

- Evitar títulos demasiadamente longos, interrogativos ou transformados em frases, os quais devem ser rejeitados por razões de estética e de objetividade;

- Evitar o início do título com artigos. Substantivos, preposições e verbos produzem melhor efeito estético;

- Resistir ao emprego de terminologia com significado subjetivo;

- Lembrar que títulos são fontes de referência, por assunto, em indexadores, os quais remetem os leitores à temática, notadamente quando colocadas as palavras-chave representativas do texto;

- Ter em mente que toda mensagem a ser transmitida pelo pesquisador, deve possuir clareza e ainda ser breve, simples e direta; - Revisar o título, ao término da sua construção, com o intuito de promover o corte de palavras desnecessárias, atentando para o fato de que, da composição do título, devem constar as variáveis e população estudadas e/ou palavras-chave.

Por oportuno, faz-se importante ser dito que o título pode ser dado por último, sem qualquer prejuízo. Mesmo assim, isso não implica elaborá-lo, sem considerar os critérios preconizados nas normas técnicas documentárias nacionais e internacionais. Afinal, a produção do conhecimento, a sua divulgação e utilização são partes de um mesmo processo: fazer ciência. 
Anexo 1

\section{UNIVERSIDADE FEDERAL DO CEARÁ \\ FACULDADE DE FARMÁCIA, ODONTOLOGIA E ENFERMAGEM \\ DEPARTAMENTO DE ENFERMAGEM}

\section{FORMULÁRIO DE COLETA DE DADOS}

\section{Dados de identificação}

Periódico

Ano VíTULO DO PERIÓDICO ___ Número___ Mês ___ N

\section{Tipo de técnica de abordagem}

( ) Qualitativa

( ) Quantitativa

\section{Tipo de linguagem}

( ) Denotativa

( ) Conotativa

\section{Figura de linguagem}

( ) Metáfora ( ) Metonímia ( ) Hipérbole ( ) Pleonasmo ( ) Nenhuma

( ) Outras - especificar

\section{Nível de linguagem}

( ) Coloquial

( ) Técnica

( ) Coloquial/técnica

\section{Concordância verbal}

( ) Correta

( ) Incorreta

\section{Concordância nominal}

( ) Correta

\section{REFERÊNCIAS BIBLIOGRÁFICAS}

1. Polit DF, Hungler BP. Nursing research: principles and methods. 5.ed. Washington: Lippincott; 1995.

2. Salomon DV. Como fazer uma monografia. São Paulo: Martins Fontes; 1991.

3. Hühne LM. Metodologia científica - cadernos de textos e técnicas. 6.ed. Rio de Janeiro: Agir; 1995.

4. Popper KR. Lógica das ciências sociais. Rio de Janeiro: Tempo Brasileiro; 1978.

5. Santos I, Clos AC. Nascentes do conhecimento em enfermagem. $9^{0}$ Seminário Nacional de Pesquisa em Enfermagem; 1997; Vitória (ES); Vitória:SE ABEn; 1997.

6. Macedo ND. Iniciação à pesquisa bibliográfica - guia do estudante para a fundamentação do trabalho de pesquisa. São Paulo: Loyola; 1994.

7. Marcantonio AT, Santos M, Lehfeld, NAS. Elaboração e divulgação do trabalho científico. São Paulo: Atlas; 1993.

8. França JL, Vasconcelos AC, Magalhães MHA, Borges SM. Manual para normalização de publicações técnico-científicas. 3.ed. Belo Horizonte: UFMG; 1996.
( ) Incorreta

Tipo de incorreção

\section{Qualidade do estilo}

Clareza ( ) sim ( ) não

Concisão ( ) sim ( ) não

Objetividade ( ) sim ( ) não

Tipo de incorreção: ( ) ambigüidade ( ) prolixidade ( ) imprecisão

( ) outra(s) - especificar

\section{Pontuação \\ ( ) Correta \\ ( ) Incorreta \\ Tipo de incorreção}

\section{Uso de redução}
( ) siglas
( ) outra(s) - especificar
( ) abreviaturas
( ) nenhuma

\section{Número de palavras usadas}
( ) Até 15
( ) mais de 15

12. Tipo de captação do título em relação às variáveis e população estudadas e/ou palavras-chave

( ) Captação adequada

( ) Captação parcialmente adequada

( ) Captação inadequada

9. Vieira S. Como escrever uma tese. 3. ed. São Paulo: Pioneira; 1996.

10. Costa AFG. Guia para elaboração de relatórios de pesquisas/ monografias - trabalhos de iniciação científica, dissertações, teses e editoração de livros. 2.ed. Rio de Janeiro: Unitec; 1998.

11. Dyniewicz AM, Martins ML. Pesquisar é preciso - escrever difícil? Cogitare Enferm 1998; 3(1):113-17.

12. Sandelowsky M. Writing a good read - strategies for re-presenting qualitative data. Nurs \& Health 1998; 21:375-82.

13. Barbosa M Filho. Introdução à pesquisa - métodos, técnicas e instrumentos. 3.ed. João Pessoa: A União; 1994.

14. Rocha R. Minidicionário. São Paulo: Scipione; 1996.

15. Ferreira ABH. Minidicionário da língua portuguesa. 3.ed. Rio de Janeiro: Nova Fronteira; 1993.

16. Silva EM. Produção, divulgação e utilização da pesquisa em enfermagem - a contribuição do Centro de Estudos e Pesquisas em Enfermagem (CEPEn) da ABEn. Anais do $7^{\circ}$ Seminário Nacional de Pesquisa em Enfermagem; 1994; Fortaleza; CE. Fortaleza: ABEnCE; 1994. p. 114. 
17. Elsen I. A pesquisa em enfermagem - como anda este processo na região sul? Anais do $7^{\circ}$ Seminário Nacional de Pesquisa em Enfermagem; 1994; Fortaleza; CE. Fortaleza: ABEn-CE; 1994. p. 71.
18. Morin E. Complexidade e transdisciplinaridade - a reforma da universidade e do ensino fundamental. Natal: EDUFRN; 1999.

19. Poyares W. $O$ carisma da comunicação humana - o fenômeno humano da comunicação. São Paulo: Elevação; 1998. 